\title{
Seedling diversity in actively and passively restored tropical forest understories
}

\author{
Jarrah Wills, ${ }^{1,6}$ John Herbohn, ${ }^{1,2}$ Jessie Wells, ${ }^{3}$ Maria Opelia Maranguit Moreno, ${ }^{4}$ \\ Angela Ferraren, ${ }^{4}$ and JenNifer Firn id 2,5 \\ ${ }^{1}$ School of Agriculture and Food Science, University of Queensland (UQ), Brisbane, Queensland 4072 Australia \\ ${ }^{2}$ Tropical Forests and People Research Centre, University of the Sunshine Coast (USC), Maroochydore, Queensland 4558 Australia \\ ${ }^{3}$ Australian Research Council Centre of Excellence for Environmental Decisions, School of Biological Sciences, The University of \\ Queensland (UQ), Brisbane, Queensland 4072 Australia \\ ${ }^{4}$ Department of Soil Science, Visayas State University, Visca, Baybay City, Leyte 6521 Philippines
}

Citation: Wills, J., J. Herbohn, J. Wells, M. O. Maranguit Moreno, A. Ferraren, and J. Firn. 2021. Seedling diversity in actively and passively restored tropical forest understories. Ecological Applications 31(3): e02286. 10.1002/eap.2286

Abstract. Alternative methods for restoring tropical forests influence the ecological processes that shape recruitment of understory species. In turn, the traits of species recruited will influence the ecological processes the forests provide now and over the long term. We assess the phylogenetic and functional structure of seedlings beneath monoculture plantations, mixed-species plantations (both active restoration) and regenerating selectively logged native forests (passive restoration), considering traits of specific leaf area (SLA, including within-species variation), leaf nitrogen and phosphorus content, life-form, potential plant height, and dispersal type. Monoculture plantations comprised seedlings that were more closely related then would be expected by chance (i.e., phylogenetically clustered), and regenerating forest contained species more distantly related then would be expected by chance (i.e., phylogenetically overdispersed). This suggests that seedlings beneath monocultures assemble through environmental filtering and through the dispersal limitation of predictable functional guilds. However, dispersal limitation is frequently overcome by human-assisted dispersal, increasing trait diversity. Comparing SLA values revealed that regenerating forests recruit seedlings with both high and low mean and variation of SLA, leading to higher overall diversity. Regenerating forest seedlings showed signs of environmental filtering, only based on within-species variation of SLA. Regenerating forest understories appear to favor species that show a high intraspecific variation in SLA values (e.g., Pterocarpus indicus Willd.) and at the same time provided habitat for later successional seedlings that show a lower intraspecific variation in SLA (e.g., Canarium luzonicum (Blume) A.Gray). This trait diversity suggests limiting similarity or competitive exclusion may be reduced because of niche differences, allowing species with different traits to coexist. Phylogenetic and functionally distinct species are restricted in their regeneration capacity, many of which are of conservation significance (under the IUCN Red List). Reforestation projects should maximize desired ecological services (including conservation value) by actively managing for the recruitment of species that are phylogenetically and functionally (including intraspecifically) distinct. This management aim will increase the probability of fulfilling a wider array of niche spaces and potentially increase the diversity of ecosystem services provided.

Key words: degraded tropical forests; emergent tree species; human-dominated landscapes; intraspecific variation; mechanistic; phylogenetic comparative ecology; recruitment.

\section{INTRODUCTION}

Understanding how and why some plant species coexist is important when attempting to restore degraded

Manuscript received 6 July 2020; accepted 16 August 2020. Corresponding Editor: Bradley J. Butterfield.

${ }^{5}$ Present address: School of Earth, Environmental and Biological Sciences Queensland University of Technology (QUT), Gardens Point Brisbane Queensland 4000 Australia

${ }^{6}$ E-mail: jarrahwills@hotmail.com plant communities, particularly in areas once occupied by highly diverse ecosystems, like tropical forests (Funk et al. 2016). Finding the optimal tropical forest restoration strategies is not straightforward, with strategies ranging from the planting of one or just a few species at a site to initiate understory recruitment of native biodiversity, to diverse ecological restoration plantings and strategies that do not require the planting of any trees (e.g., regenerating secondary forest; Lamb et al. 2005). In highly modified tropical landscapes, a combination of 
monocultures and mixed-species plantations, high-diversity restoration plantings, and natural regeneration of secondary forests have been found to provide different benefits for biodiversity and ecosystem function (Barlow et al. 2007, Wills et al. 2017). What is not well understood is how the restoration strategy used impacts on the mechanisms that drive understory plant community assembly. Unpacking the mechanisms acting on the recruitment of plant species in the understories of, for example, monocultures vs. more diverse restoration focused strategies may provide a mechanistic underpinning for future attempts at restoring tropical forests (Hector et al. 2011, Cadotte et al. 2017).

Environmental filtering and interactions between species are key mechanisms acting on the assembly of plant communities (Silvertown 2004). Environmental conditions, such as rainfall, soil nutrient and light availability, provide conditions that potentially favor the recruitment and survival of some species over others. This essentially selects for species with traits that are suited to the abiotic conditions, which leads to trait similarity. Whereas biotic interactions such as competition can limit how similar traits are between species presumably as species are more likely to be in competition for the same niche space (Grubb 1977). The relative importance of environmental filtering and competitive interactions can potentially be teased apart by measuring the phylogenetic and functional structure of plant communities (Ricklefs 2008, Baraloto et al. 2012).

If functional traits are conserved amongst related species or inherited over evolutionary timescales, a community's phylogenetic and functional structure may be found to be either clustered (i.e., community members are more closely related and display a higher similarity in trait values than would be expected by chance alone) or overdispersed (i.e., community members are more distantly related and display a higher dissimilarity than would be expected by chance alone; Webb 2000, Cavender-Bares et al. 2004, Kraft and Ackerly 2010). Niche theory predicts that the assembly of clustered communities is explained by environmental filtering, as a reflection of species adaptations to their shared environment (Webb et al. 2002, Cornwell et al. 2006, Pausas and Verdú 2010). Overdispersed communities are explained by competitive interactions between species that have similar resource requirements and growing habits, potentially resulting in competitive exclusion and greater niche differentiation (Pausas and Verdú 2010). However, competitive interactions may not simply lead to overdispersion in either traits or phylogenetic structure, because of the opposing effects of niche differences (altering the balance between intra- and interspecific competition, and tending to stabilize coexistence) vs. differences in competitive ability (which could involve a narrow range of trait values and actually lead to clustering) and important functional traits may not be conserved phylogenetically (Mayfield and Levine 2010).
Phylogenetic approaches have rarely been applied to understanding reforestation methods (but see Verdú et al. 2012, Hipp et al. 2015, Schweizer et al. 2014, 2015) and studies of reforestation have focused more on positive biotic interactions, such as facilitation and successional development (Letcher 2010, Norden et al. 2011, Shooner et al. 2015). Valiente-Banuet and Verdú (2007) found that regeneration niches are conserved across evolutionary time. They argue that positive interactions (i.e., facilitation) occur between phylogenetically distant species and that facilitation can lead to phylogenetic overdispersion. Increased seedling phylogenetic diversity can also have a positive influence on survival via phylogenetically correlated pathogen susceptibilities, which can lead to density-dependent selection (Webb et al. 2006). As further evidence of the importance of phylogenetic diversity, in a comprehensive meta-analysis co-occurring plant species from the same life form were more likely to survive if they were distantly related (Verdú et al. (2012).

In this study, we measure the phylogenetic and functional diversity of seedling recruitment beneath different passive and active reforestation methods across a degraded tropical forest landscape on the Island of Leyte in the Philippines. The reforestation methods we compare ranged from low- to high-diversity forests, in the form of monoculture plantations of the exotic species Swietenia macrophylla King, mixed-species plantations, and regenerating selectively logged native forests. We analysed both phylogenetic and functional traits, including intraspecific variability in specific leaf area (SLA). Intraspecific variability in SLA allowed us to consider how phenotypically plastic the traits of recruited species were in the understory of these forest types. We specifically address the following three questions: (1) What is the phylogenetic and functional trait structure (SLA, leaf nutrients, life form, potential plant height, and dispersal type) of seedling communities beneath different reforestation types? (2) What is the intraspecific variation of SLA observed in the different forest types, and between species and groups that are common or obligate across forest types? (3) What do the phylogenetic structure, functional trait structure, and intraspecific variation in SLA tell us about how seedling communities assemble in the understories of these different forest types?

We expected to find a shift in the main assembly patterns between seedling communities beneath the different reforestation methods, from environmental filtering under monoculture forests (where species colonization is limited by dispersal and abiotic conditions) to competitive exclusion within regenerating selectively logged forest, which are more diverse in terms of species and microclimates. We also expected to find that seedlings beneath regenerating selectively logged forests and mixed-species plantations will show greater intraspecific variation in SLA because of the greater environmental and biotic variation in these forests (e.g., in light levels, 
topography, and leaf litter composition) and potentially reflecting genetic variation.

\section{Materials And Methods}

\section{Study sites and data collection}

The study was undertaken on the Island of Leyte in the Philippines (between $124^{\circ} 17^{\prime}$ and $125^{\circ} 18^{\prime}$ E longitude, and between $9^{\circ} 55^{\prime}$ and $11^{\circ} 48^{\prime} \mathrm{N}$ latitude). Leyte has an average annual rainfall of 2,753 $\mathrm{mm}$ and an average annual temperature of $27.5^{\circ} \mathrm{C}$. All plants below $2 \mathrm{~m}$ in height were sampled within a total of 35 circular plots (individual plot area $=78 \mathrm{~m}^{2}$ ) that were spread across 15 sites. Most sites had two or three plots, except for one (Appendix S1: Table S1). These sites included five mahogany (Swietenia macrophylla King) monoculture plantations, five mixed-species plantations (known locally and hereafter as "rainforestation"), and five regenerating selectively logged native forests. On the island of Leyte and in the Philippines in general, it is challenging to find primary forest sites and therefore the regenerating selectively logged native forests were chosen for this study as the best examples available of more intact natural forests. Sites occurred at elevations of less than $600 \mathrm{~m}$ above sea level and, with one exception, had soils of volcanic origin, and were previously located within the same vegetation type. Plantations were between 13 and $18 \mathrm{yr}$ of age at the time of sampling. Regenerating selectively logged native forest sites had higher average slope angles and elevations than plantations, were logged relatively recently ( $\sim 20 \mathrm{yr})$ and, at the time of sampling, were frequently used by nearby communities for the harvesting of non-timber forest products (NTFPs). At each of the plantation locations, the distances to potential seed sources, as the regenerating selectively logged native forests, were measured using Google Earth imagery and verified in the field. Plantations were located at similar distances from potential seed sources (Appendix S1: Table S1, Fig. S1; Nguyen et al. 2016, Wills et al. 2017).

Plant identification was verified with several local experts at Visayas State University, Leyte Island. A CID Bio-Science CI-110 Plant Canopy Imager (Camas, WA, USA) was used to measure leaf area index (LAI) and the average of three readings per plot measured at $1.3 \mathrm{~m}$ above ground level was used in the analysis, where higher values represent more closed canopies.

\section{Functional traits}

Three continuous traits were measured: SLA $\left(\mathrm{cm}^{2} / \mathrm{g}\right)$, leaf nitrogen concentration (hereafter, LNC, as a percentage of dry leaf mass) and leaf phosphorus concentration (hereafter, LPC, as a percentage of dry leaf mass), generally following the protocols set out by Pérez-Harguindeguy et al. (2013). We collected a minimum of two leaves per seedling for all tree and shrub species recorded in the plots. The youngest mature fully expanded leaves were collected, but leaf traits were not collected if it was judged to be detrimental to the individual's survival because of only a few leaves being available. Collected leaves were placed into a paper bag, labelled, and scanned using a CID Bio-Science CI-203 Laser Area Meter. Leaf area scanning was conducted either onsite or in the afternoon of the same day. Leaf samples were oven dried at $65^{\circ} \mathrm{C}$ for $48 \mathrm{~h}$ and weighed to calculate SLA. To determine LNC and LPC (see Appendix S1: Section S1 for soil N and P methods), samples were prepared with a single digestion method and analysed with a colorimetric determination of LNC using the salicylate-hypochlorite method developed by Baethgen and Alley (1989) and LPC using an adaptation of Murphy and Riley (1962) single solution method (Anderson and Ingram 1989).

Specific leaf area was sampled for 856 individual plants, representing 91 identified species from a sampled total of 2,899 individuals from 219 species. LNC and LPC were analysed on a subset of the species used for the calculation of SLA, which included 127 individual plants representing 53 species. For intraspecific variation of SLA, initially all species with more than one SLA measurement were used, and a minimum of five individuals per species are presented within the results, limiting the number of species that were analysed to 39 .

Data on three categorical traits, which were scored on an ordinal scale were extracted from open databases (see database list in Appendix S1) and primary literature for a total of 123 species; dispersal type (abiotic or biotic), potential plant height was coded with four levels (1, understory, 0-5 m; 2, mid-canopy, 6-15 m; 3, canopy, 16$30 \mathrm{~m}$; 4, emergent, $30 \mathrm{~m}+$ ), and life form was coded with five levels (1, herb; 2 , vine/liana; 3 , palm; 4 , shrub; 5 , tree). The species were composed of 13 herbaceous species, 1 palm species, 13 shrub species, 93 tree species, and 3 vine/liana species.

\section{Community phylogeny}

The regional species pool can have significant influences on the local phylogenetic structure (Lessard et al. 2012), statistical inferences, and subsequent conclusions regarding community assembly processes (Pigot and Etienne 2015). Therefore, we contextualize the present study within broader evolutionary temporal and spatial scales. The Philippine flora, in particular the MindanaoEastern Visayas tropical forest (that includes the island of Leyte), has a dominant affiliation with the Asia/Malesia floristic province, but also includes Gondwanan relicts such as the southern gymnosperms (e.g., Podocarpus rumphii Blume and Agathis philippinensis Warb; Langenberger et al. 2006, Sniderman and Jordan 2011). These Gondwanan lineages have extremely long divergence times relative to all other lineages.

The community phylogeny was constructed using a regional species pool consisting of all 125 seed-plant 
species recorded in the understory of all forest types. (Five non-seed plants were excluded due to their extremely early divergence relative to all other species, which would have eclipsed the phylogenetic distances among seed plants). The 125 seed plants consisted of 124 angiosperms and 1 gymnosperm (Agathis philippinensis). This gymnosperm was included in traits analyses, but excluded from phylogenetic diversity analysis due to its long phylogenetic distance compared to other species (Cavender-Bares et al. 2006, Cadotte 2014). Of the total 125 species used (124 angiosperms for phylogenetic diversity), 95 were native and 30 were classified as recently introduced. The phylogenetic structure was analysed using three taxonomic subsets: (1) all angiosperm species (i.e., excluding the gymnosperm), (2) all angiosperm species excluding recently introduced species, and (3) all angiosperm species excluding monocot species (i.e., tree, shrub and herbaceous species). Chronograms are approximate or "pseudo" chronograms because single fixed points were assigned for "known" ages, and all other divergences were assumed to be evenly distributed between them (see Appendix S1: Section S1). These subsets were used to decipher their influence on the phylogenetic structure of the different seedling communities (Appendix S1: Table S1).

For a detailed description of the methods used to age, the phylogenetic tree refers to the community phylogeny section within Appendix S1: Section S1.

\section{Data analysis}

Analyses were conducted using $\mathrm{R}$ statistical computing version 3.1.1 (R Core Team 2013) and Phylomatic command Version 3 (Webb et al. 2008).

Phylogenetic structure was quantified using phylogenetic diversity (PD), mean pairwise phylogenetic distance (MPD) and mean nearest taxon phylogenetic distance (MNTD) for both incidence- and abundancebased methods (Webb et al. 2002). The patterns of phylogenetic structure between forest types were analysed using nodesigl command from Phylocom 4.2 (Appendix S1: Section S1; Webb et al. 2008). The functional structure was quantified using the same metrics as the phylogenetic structure; mean pairwise functional traits distance (MFD) and mean nearest functional traits distance (MNFD; Li et al. 2015). Trait distances were constructed using a Euclidian distance matrix for continuous traits both individually and together. For categorical traits (that included missing data), a Gower distance matrix was constructed within the FD package in R (Gower 1971, Laliberté and Legendre 2010, Laliberté et al. 2014). To test for differences in the seedling phylogenetic and functional structure beneath different forest types, taking into consideration unequal sample sizes and species richness, we compared analyses to a null model that randomized the species identity at the plot level with species drawn from the regional species pool, using 1,000 null iterations. To do this, we created standardized effect sizes (SES) in the picante R package (Kembel et al. 2010). Traits were analysed both in isolation and including all traits, and when limited to native species.

We used linear mixed effect models (LMEMs), estimated using maximum likelihood, to compare the phylogenetic and functional structure between forest types and how this varied depending on the abiotic conditions (e.g., soil phosphorus, soil nitrogen, and LAI). To account for our sampling design, random effects were structured as plots nested within sites. The $\mathrm{R}$ package nLME was used to fit all LMEMs and because the experimental design is largely balanced, Wald $F$ statistics were used to assess the significance of the fixed effects (Pinheiro et al. 2016). The effects package (Fox 2016) from $\mathrm{R}$ was used to display the higher-order fixed effects.

For more details on how we identified patterns of phylogenetic structure between forest types, how we tested relationships between traits (SLA, LNC, and LPC) taking into consideration phylogenetic covariance and how we tested for phylogenetic signal of both continuous and discrete traits, see Appendix S1: Section S1.

\section{Results}

What is the phylogenetic and functional trait structure of
seedling communities beneath the different forest types?

Phylogenetic diversity.-Overall, seedling communities were phylogenetically overdispersed within regenerating selectively logged forests (passive restoration) and clustered within monoculture forest types (active restoration; Figs. 1, 2). However, this pattern could not be differentiated in some cases from random assembly processes. In general, this pattern was robust to different null models, species pools (e.g., all species, natives, trees, and shrubs) and pseudo-chronograms, i.e., one pseudo-chronogram based solely on Wikström et al. (2001) ages and one incorporating Bayesian estimates (Appendix S1: Table S1).

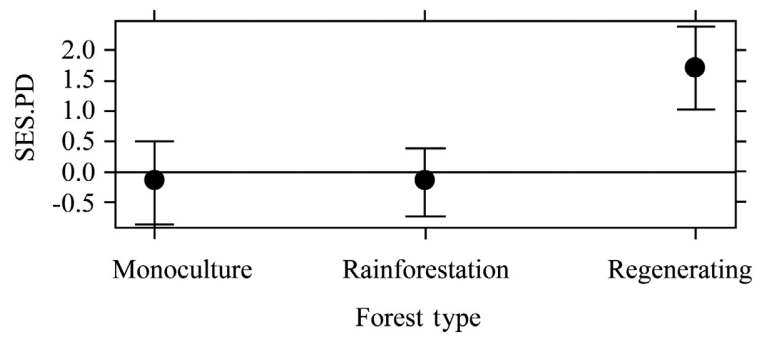

FIG. 1. Phylogenetic diversity in different forest types. Phylogenetic diversity (PD) was compared to null model distributions (standardized effect sizes, SES) of understories beneath monoculture, rainforestation, and regenerating selectively logged forests. Positive values indicate overdispersion whereas negative values indicate clustering. This model was statistically significant $(P<0.05)$, using $F$ statistics. Error bars show \pm SE. 
Phylogenetic diversity
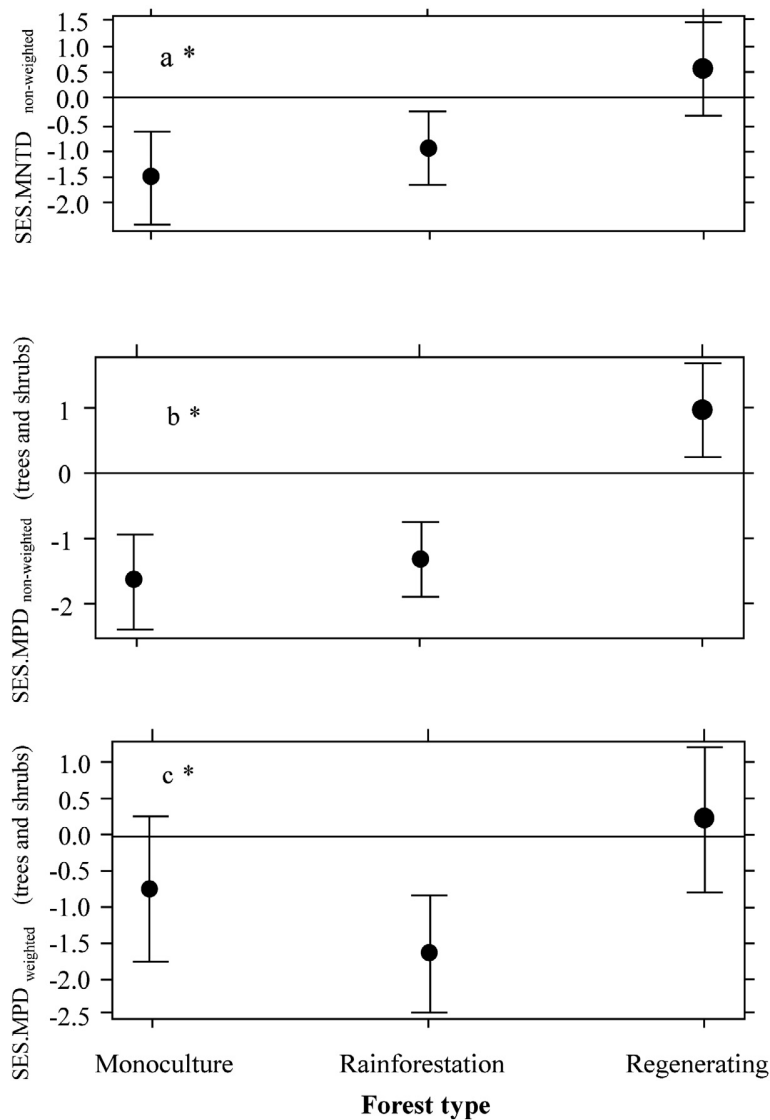

Leaf trait diversity


FIG. 2. Understory phylogenetic and leaf trait diversity beneath monoculture, rainforestation, and regenerating selectively logged forests. Phylogenetic and leaf trait structure were measured against standardized effect sizes (SES) for (a) non-weighted mean nearest taxon phylogenetic distance (MNTD) for all species, (b) non-weighted mean pairwise phylogenetic distance (MPD) for tree and shrub species in isolation, (c) weighted mean pairwise phylogenetic distance (MPD) for tree and shrub species in isolation, (d) non-weighted mean pairwise functional distances (MFD) of specific leaf area (SLA), (e) non-weighted MFD of leaf nitrogen concentration (LNC), and (f) non-weighted MFD of log-transformed leaf phosphorus concentration (LPC). The phylogeny incorporating Bayesian estimates of divergence times and a functional trait dendrogram were used as the basis of the displayed metrics. Positive values indicate overdispersion and negative values indicate clustering compared to the null model expectations that used species richness to randomize the phylogeny and dendrogram. The astericks represent a significant relationship. Error bars show \pm SE.

Observed PD was higher within the regenerating selectively logged forest sites $\left(F_{2,12}=9.0, P=0.03\right)$ and differed depending on soil nitrogen $\left(F_{1,17}=5.51\right.$, $P=0.03)$. PD between forest types also differed from the null model expectations when all species were included in the models $\left(F_{2,12}=4.6, P>0.03\right)$, and varied depending on soil phosphorus $\left(F_{1,17}=4.9, P=0.04\right.$; Fig. 1). The PD of tree and shrub species differed from null expectations between forest types $\left(F_{2,12}=9.26\right.$, $P>0.004)$ and $\operatorname{LAI}\left(F_{1,17}=6.62, P=0.02\right)$.

The non-weighted MNTD for all species, and when restricted to trees and shrubs, and natives, differed from the null model expectations (all species $F_{2,12}=3.95$, $P=0.05$; tree and shrub $F_{2,12}=9.74, P=0.003$; and natives $F_{2,12}=6.56, P=0.01$ ), with regenerating selectively logged forest seedlings being overdispersed and monoculture and rainforestation plantations being more similar and clustered (Fig. 2).

Associations between phylogenetic groups and forest types.-The family Meliaceae (Swietenia macrophylla, Sandoricum koetjape (Burm.f.) Merr., Lansium domesticum Correa, and Dysoxylum gaudichaudianum (A.Juss.) Miq.) contributed significantly more taxa to seedling communities beneath the monoculture forest types than by chance as revealed using the nodesigl function (Phylocom 4.2). The family Moraceae (Ficus septica Burm.f., F. pseudopalma Blanco, F. nota (Blanco) Merr., Artocarpus odoratissimus Blanco, and A. blancoi (Elmer) Merr.) also contributed more taxa than by chance within monoculture forest types, when restricting the analysis to native species. An overabundance of seedlings from the 
genus Ficus (that included seven species) was found within the regenerating selectively logged forests.

Functional diversity. - Overall, understory leaf traits suggest weaker trends to phylogenetic structure, with some evidence of overdispersion under the regenerating selectively logged forest and clustering within monoculture forest seedling communities. However, this relationship was weak, and could not be statistically differentiated from random patterns. Functional diversity differed between restoration types except in the case of the mean SLA values per plot $\left(F_{2,12}=9.0, \quad P=0.004\right.$; Appendix S1: Table S3). Using SLA, abundanceweighted and non-weighted MFD displayed overdispersion for regenerating selectively logged forests, while monoculture and rainforestation sites were similar and clustered (Fig. 2). The non-weighted MNFD for SLA and LNC varied depending on soil nitrogen (SLA $F_{1,17}=4.7, \quad P=0.044 \quad$ and $\quad$ LNC $\quad F_{1,17}=6.47$, $P=0.021)$.

In contrast, analysis of the functional structure incorporating categorical traits of potential plant height, dispersal type, and life form suggests a reverse in the patterns generally found using phylogenies and, to a lesser extent, leaf traits. The weighted SES.MFD using all traits tended toward overdispersion within monoculture forests and random to clustering within the Rainforestation and regenerating selectively logged forests (Fig. 3a). When restricting the analysis to native species, the


FIG. 3. Higher-order fixed effects from linear mixed-effect models (LMEMs) for understory functional diversity (life form, potential plant height, dispersal type, SLA, LNC, and LPC), measured as standardized effect sizes of abundance-weighted MFD for (a) all species and (b) for native species in isolation beneath the different forest types. A Gower distance matrix was constructed, as it allows for categorical and missing data. Error bars show \pm SE. rainforestation forest type switched from random to overdispersed (Fig. 3b). Within the monoculture forests, weighting by species' relative abundances using the MFD and MNFD of all traits resulted in an increase toward overdispersion compared to the null model.

Phylogenetic and functional trait relationships. - Considering phylogenetic covariance, the tallest trees and native species were significantly more likely to be wind-dispersed (trees, $z=2.98, P=0.003$ and natives, $z=2.289$, $P=0.02)$. However, this trend was not detected when using the entire species pool (all species, $z=0.958$, $P=0.34$ ). SLA had a positive relationship with LNC but not with LPC after accounting for phylogenetic covariance $\left(F_{1,51}=24.47, P \leq 0.0001\right)$.

LPC and LNC exhibited significant phylogenetic signals compared to a Brownian motion model of evolution $(P<0.05)$, with LPC showing higher $K$ values $(K=0.528)$ than both LNC $(K=0.419)$ and SLA ( $K=0.285$, nonsignificant). Due to the high number of replicates for SLA, we analysed phylogenetic signal considering sampling error and/or intraspecific variation, and this increased the $K$ value for SLA considerably $(K=0.436)$. Significant phylogenetic signals $(P<0.05)$ were also found for life form, dispersal type, and potential plant height (Appendix S1: Table S4).

\section{SLA mean and variation beneath the different forest types and between common or obligate clades}

Average seedling SLA values at the plot level were significantly higher in the monoculture forest type than in the regenerating selectively logged forests, while the rainforestation forest types were intermediate $\left(F_{2,12}=10.3\right.$, $P=0.003)$. The weighted community mean SLA values showed a similar trend; however, evidence of this relationship was not significant $\left(F_{2,12}=1.02, P=0.4\right)$. The plot-level CV was significantly higher within regenerating selectively logged forests than monoculture forests and the rainforestation forest type was again intermediate $\left(F_{2,12}=6.59, P=0.012\right.$; Fig. $\left.4 a\right)$.

Taking into account differences in species richness and only using species with adequate replication (five or more individuals per species) for SLA measurements; we found regenerating selectively logged forests included species with both high and low intraspecific variation in SLA (e.g., higher variation in SLA, Pterocarpus indicus Willd, Koordersiodendron pinnatum Merr. and Neolitsea vidalii Merr; lower variation in SLA, Canarium luzonicum (Blume) A.Gray, Diplodiscus paniculatus Turcz, Ficus balete, and Shorea contorta S.Vidal; Appendix S1: Figs. S2, S3). This resulted in a significant overdispersion of $\mathrm{CV}$ in the weighted SESMNFD $\left(F_{2,12}=15.32\right.$, $P \leq 0.001)$ and SESMFD $\left(F_{2,12}=14.91, P=<0.007\right.$; Fig. $4 \mathrm{~b}, \mathrm{c})$, and non-weighted SESMNFD $\left(F_{2,12}=5.99\right.$, $P=0.016)$ and SESMFD $\left(F_{2,12}=5.82, \quad P=0.017\right)$ within regenerating selectively logged forest seedling communities and clustering within the monoculture and 

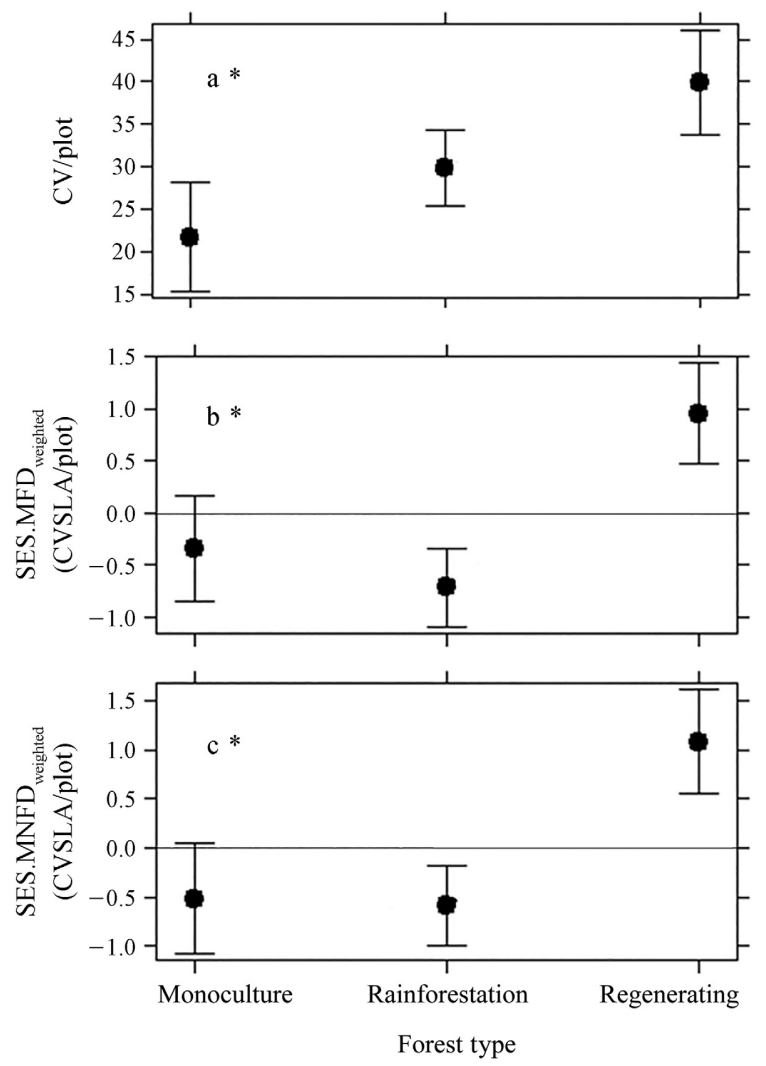

FIG. 4. Higher-order fixed effects for mean coefficient of variation (CV) for (a) SLA values of all individuals at the plot level and (b) MFD and (c) MNFD weighted by abundances for species with five or more SLA replicates between monoculture, rainforestation, and regenerating selectively logged forests seedling communities. An asterisk * denotes a significant relationship overall $(P<0.05)$. Error bars show \pm SE

rainforestation forest types. Weighted SESMNFD and SESMFD also varied depending on soil nitrogen (Appendix S1: Table S5).

The Moraceae family was common across forest types and generally showed higher than average $\mathrm{CV}$ values for SLA ( 18 to $\sim 34)$. The monoculture grown species $S w i-$ etenia macrophylla showed a relatively lower than average CV in SLA ( 16). Species within the family Dipterocarpaceae that were absent within the monoculture forests showed a relatively low CV in SLA ( 14-16). Wind-dispersed species had representatives that showed both a higher variation in SLA (e.g., Pterocarpus indicus) and a lower variation in SLA (e.g., Dipterocarpaceae species) (Table 1; Appendix S1: Table S5).

\section{Discussion}

Overall, we found that seedling communities recruited using active restoration methods for example beneath mahogany monocultures were likely recruited because of environmental filtering as these seedling communities were found to be more closely related than by chance. In contrast, seedling communities within passive methods such as regenerating selectively logged forest, this studies more "natural" baseline communities, showed evidence of competitive processes explaining their compositional makeup as these seedling communities were more distantly related than would be expected by chance. Further analyses that also considered intraspecific variation in SLA, found that the assembly of seedling communities beneath regenerating selectively logged forests was likely explained by both environmental filtering and competitive interactions (see Fig. 5 for a summary conceptual diagram of community assembly processes; Norden et al. 2011).

As expected, the more structurally complex and diverse regenerating selectively logged forests likely showed a greater fulfilment of niche space within seedling communities when compared to monocultures (Letcher 2010). The rainforestation forests showed intermediate fulfilment of niche space between the other forest types, suggesting that more diverse plantations may not necessarily in the short-term capture true differences in species effects on ecosystem functions (Lamb et al. 2005). Within the regenerating selectively logged forests there is a greater occurrence of more phylogenetically and functionally divergent seedling species, and these species show both high and low abilities to adjust their SLA values.

These results highlight the need for incorporating greater phylogenetic and functional diversity in reforestation projects, which may not equate to increasing pure species numbers, but also provides for surrogate measures of differences in how species potentially influence ecosystem function. This could result in reforestation interventions that lead to a greater niche fulfilment by seedling communities regenerating under planted forests, and therefore more functionally rich future forests that can better adapt to future environmental conditions and provide a different range of ecosystem services. To do this, we recommend the promotion of phylogenetically and functionally broader ranges of seed or seedling stocks in reforestation schemes across degraded tropical landscapes. In particular, efforts should be made to include native emergent, wind-dispersed tree species (Wills et al. 2017), species from other limited functional groups (e.g., large-seeded species), and species with a broader range of mean SLA values and levels of intraspecific variation in SLA.

Rainforestation sites, although planted with a much higher number of species than monocultures, were generally not statistically different phylogenetically or functionally from the other forest types and from random assembly processes. These results partly support our initial predictions that community assembly in monoculture seedling communities is more strongly influenced by environmental filtering and dispersal limitation. Regenerating selectively logged forest, which had higher diversity and more complex canopies and understories that have assembled for considerably longer time periods, 
TABLE 1. Intraspecific variation of specific leaf area (SLA) for common and obligate species.

\begin{tabular}{|c|c|c|c|}
\hline Family and species & Forest type present & SLA-n & Species CV \\
\hline \multicolumn{4}{|l|}{ Moraceae (+M) } \\
\hline Ficus septica $(+\mathrm{S})$ & common & 21 & 18.4 \\
\hline Ficus pseudopalma $(+\mathrm{S})$ & common & 25 & 33.8 \\
\hline Ficus nota $(+\mathrm{S})$ & common & 20 & 28.1 \\
\hline Artocarpus odoratissimus & common & 39 & 18.4 \\
\hline Artocarpus blancoi & common & 24 & 23.5 \\
\hline \multicolumn{4}{|l|}{ Meliaceae $(+\mathrm{M})$} \\
\hline Swietenia macrophylla & obligate (M) & 49 & 16.2 \\
\hline Sandoricum koetjape & common & 5 & 23.9 \\
\hline Lansium domesticum & obligate (M and $\mathrm{R}$ ) & 5 & 35 \\
\hline Dysoxylum gaudichaudianum & obligate (M and $\mathrm{S}$ ) & 6 & 10.8 \\
\hline \multicolumn{4}{|l|}{ Dipterocarpaceae $(-\mathrm{M})$} \\
\hline Shorea contorta & obligate (R and $\mathrm{S}$ ) & 43 & 13.6 \\
\hline Hopea plagata & obligate ( $\mathrm{R}$ and $\mathrm{S}$ ) & 21 & 15.9 \\
\hline \multicolumn{4}{|l|}{ Fabaceae } \\
\hline Pterocarpus indicus $(-\mathrm{M})$ & obligate ( $\mathrm{R}$ and $\mathrm{S}$ ) & 16 & 36.5 \\
\hline \multicolumn{4}{|l|}{ Clusiaceae } \\
\hline Calophyllum inophyllum (-M) & obligate (S) & 6 & 15.7 \\
\hline \multicolumn{4}{|l|}{ Burseraceae } \\
\hline Canarium luzonicum $(-\mathrm{M})$ & obligate (S) & 7 & 7.9 \\
\hline
\end{tabular}

Notes: The coefficient of variation $(\mathrm{CV})$ for clades that represent common and obligate groups between monoculture $(\mathrm{M})$, rainforestation (R), and regenerating selectively logged forest types (S). Plus (+) signs represent a statistical overabundance of those clades within the corresponding community compared to a null model that randomly assigned the same number of species from the same species pool (nodesig statistic; Webb et al. 2008). Minus (-) signs represent a lack of that species or family within the corresponding forest type.

showed evidence of more phylogenetically and functionally diverse seedling communities, likely indicating stronger competitive interactions. Lower stem densities within the monoculture forest type compared to the regenerating selectively logged forest likely reduced the competitive interactions between monoculture seedling communities, irrespective of phylogenetic or functional relatedness.

When we considered potential plant height, life form, and dispersal type, rainforestation and regenerating selectively logged forest seedling communities could not be differentiated from random, which means these traits are less variable in the higher-diversity forest types compared to a random subset of the species pool. Unexpectedly monocultures displayed higher overdispersion when considering these same traits. Examining the identity of the seedling species found in the monoculture, this finding is likely explained by the introduction of functionally distinct species that are readily eaten and dispersed by local people or weed species that are favored by disturbance, such as wind-dispersed herbs and shrubs; Crotalaria spp., Chromolaena odorate (L.) R.M.King \& H.Rob. (Siam weed), Sphagneticola trilobata (L.) Pruski (Singapore daisy), and smaller-stature trees Theobroma cacao L. (cacao) and Psidium guajava L. (guava).

When restricting the analysis to native species or just tree species, taking phylogenetic covariance into consideration, we found that wind-dispersed tree species displayed the tallest potential heights. This result is consistent with a previous study on the same forest types, where we found that native wind-dispersed tree species are limited across the studied forest types and are the tallest trees at maturity, further supporting their occurrence as important emergent tree species within tropical forests (Wills et al. 2017). It is clear from both studies that wind-dispersed tree species are recruitment limited within these monoculture forests and have narrowed the range of traits available within these communities.

We expected the regenerating selectively logged forest seedling communities to show a higher within-species variation in SLA, due to more complex canopy structures and therefore understory species being exposed to varied environmental and biotic conditions. This was supported with the regenerating selectively logged forest seedlings comprising species with a high SLA variation (e.g., Pterocarpus indicus, Neolitsea vidalii, and Palaquium foxworthyi Merr.), but also species with a lower variation in SLA (e.g., Canarium luzonicum, Diplodiscus paniculatus, Ficus balete, and Shorea contorta). These results extend our initial predictions, indicating that both environmental filtering and competitive exclusion may be operating within regenerating selectively logged forest seedling communities; whereas within monoculture seedling communities, environmental filtering and dispersal limitation are likely more prominent, but human-assisted recruitment appears to overcome this filtering in some cases (Fig. 5). 


\begin{tabular}{|c|c|c|c|c|c|c|}
\hline Forest type & $\mathrm{SR} / \mathrm{PD}$ & Species composition & Evolutionary & Leaf traits & Discrete traits & SLA (CV) \\
\hline Regenerating & Higher & & $\begin{array}{l}\text { Competitive } \\
\text { exclusion }\end{array}$ & $\begin{array}{l}\text { Competitive } \\
\text { exclusion } \\
\text { - random }\end{array}$ & $\begin{array}{l}\text { Environmental } \\
\text { filtering }\end{array}$ & $\begin{array}{l}\text { Competitive } \\
\text { exclusion } \\
\text { Environmental } \\
\text { filtering }\end{array}$ \\
\hline Reforestation & & & $\begin{array}{l}\text { Environmental } \\
\text { filtering }\end{array}$ & $\begin{array}{l}\text { Environmental } \\
\text { filtering } \\
\text { - random }\end{array}$ & $\begin{array}{l}\text { Environmental } \\
\text { filtering }\end{array}$ & $\begin{array}{l}\text { Environmental } \\
\text { filtering }\end{array}$ \\
\hline Monoculture & Lower & & $\begin{array}{l}\text { Environmental } \\
\text { filtering }\end{array}$ & $\begin{array}{l}\text { Environmental } \\
\text { filtering } \\
\text { - random }\end{array}$ & $\begin{array}{l}\text { Competitive } \\
\text { exclusion }\end{array}$ & $\begin{array}{l}\text { Environmental } \\
\text { filtering }\end{array}$ \\
\hline
\end{tabular}
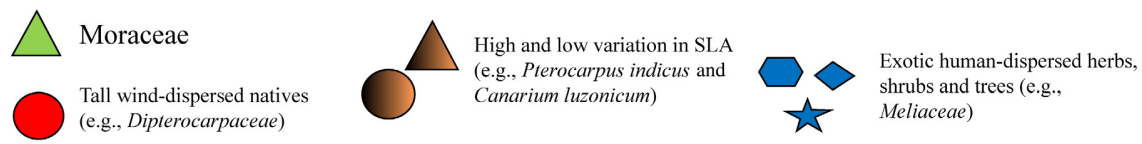

FIG. 5. Summarizing community assembly processes indicated by analyzing evolutionary, leaf trait (SLA, LNC and LPC), discrete trait (potential height, dispersal, and life form) and within-species SLA data, for regenerating selectively logged forest (regenerating), rainforestation, and monoculture forest types. Species richness (SR) and phylogenetic diversity (PD) were highest within regenerating selectively logged forest and lowest within monoculture forest types, rainforestation was intermediate. Species within the family Moraceae (green) were common across forest types and tall, wind-dispersed native species (red) were limited to regenerating selectively logged forest and rainforestation forest types. Species that exhibited high and low variation in SLA (brown gradient) were also restricted to regenerating selectively logged forest seedling communities. Exotic human-dispersed herbs, shrubs, and trees (blue) increased all measures of seedling diversity within monoculture forest types.

\section{Phylogenetic and functional structure beneath forest types}

The mechanism behind the overdispersion in categorical traits (potential plant height, life form, and dispersal type) within monoculture seedling communities is driven by the introduction of functionally distinct exotic species, both directly (via human dispersal of seeds) and indirectly (invasion of species/traits due to habitat modification and vacant niche space). The understories within the monoculture forest type contained related species that possess traits that enable them to overcome dispersal limitations. For example, the family Moraceae typically have very small seeds and are dispersed by habitat-generalist bird species. This role for dispersal limitation has been illustrated across the tropics (Corlett 2006). Our results revealed that the family Meliaceae also exhibited an overabundance within the monoculture forest type, likely from human-assisted dispersal of edible species with a large fruit size (e.g., Sandoricum koetjape and Lansium domesticum). Primates are known to be important dispersal agents in tropical forests and are responsible for the dispersal of many large-fruited species' (Chapman 1989). Here, we find that humans are also key dispersal agents for functionally distinct exotic species due to the close physical relationship these small-scale community-managed forests have with local people.
Assessing the value of seedling biodiversity beneath monoculture forest types depends largely on the desires of landholders and the relative importance of conservation and socioeconomic values. Nonnative understory species contribute to ecosystem function and subsequent services. However, if dominated by few species these understories may lack the ecological complexity and ecosystem services associated with increased leaf trait and phylogenetic diversity (e.g., ecosystem resilience to invasion and to a changing climate).

\section{Intraspecific variation in SLA}

It is now widely recognized that there is a large amount of intraspecific variation in key plant functional traits including SLA (Cavender-Bares et al. 2006, Swenson and Enquist 2009, Messier et al. 2010), and that this variation can have implications for coexistence and improvements in detecting underlying community assembly processes (Ashton et al. 2010, Jung et al. 2010, Burns and Strauss 2012). Our results suggest that incorporating information on intraspecific variation in SLA can extend our understanding of seedling community assembly. Our findings showed that regenerating selectively logged forests recruit species with both high and low variation in SLA. Therefore, these forests appear to provide habitat for later successional species with 
conservative leaf economies and low variation in SLA (Walters and Reich 1999), as well as, species that have higher variation in SLA, due to genetic diversity or environmental acclimation.

Previous studies have found variation in SLA is due to both abiotic conditions (e.g., soil and light) and competitive interactions (Bloor and Grubb 2004, Burns and Strauss 2012). Our results support these findings, and with this relationship likely explained by the more varied abiotic and biotic conditions found in the understory of regenerating selectively logged forests compared to the other forest types.

Species in the Moraceae family, and particularly the genus Ficus, were abundant across all of the studied forest types. Members of the Moraceae family, and particularly the genus Ficus showed a larger than average variation in SLA, in all forest types. Native wind-dispersed species, which are limited in their recruitment ability across the studied forest types (Wills et al. 2017), show both relatively high and low variation in SLA. The leguminous wind-dispersed species Pterocarpus indicus showed a very high SLA variation. In contrast, other wind-dispersed native species including species within the family Dipterocarpaceae all showed relatively belowaverage species-specific mean SLA and variation in SLA. This likely reflects their later successional status and a more conservative resource acquisition strategy on the leaf economic spectrum (Walters and Reich 1999, Wright et al. 2004).

\section{CONCLUSION}

Analyzing the phylogenetic and functional diversity beneath different reforestation methods and comparing these to relatively more intact native forests has identified evolutionary lineages and functional groups that are restricted in their regeneration capacity and will influence future ecosystem functioning across the Island of Leyte. These include several species listed under The International Union for Conservation of Nature Red List of Threatened Species, including the Vulnerable Canarium luzonicum, Pterocarpus indicus, Agathis philippinensis, and Neolitsea vidalii, and the Critically Endangered Hopea plagata S.Vidal and Shorea contorta. Our findings provide direct evidence that the design of forest plantations should consider species diversity, functional diversity, and phylogenetic distance but, in the shortterm, even plantations with highly diverse overstories may lack key functional and phylogenetic groups found in remnant native forests, particularly in tropical rainforests ecosystems.

\section{ACKNOWLEDGMENTS}

We would like to thank staff and students at Visayas State University for their knowledge, and expertise. This project was conducted as part of an ACIAR Project ASEM/2010/050; Improving watershed rehabilitation outcomes in the Philippines using a systems approach. J. Wills and J. Firn designed the study; J. Wills performed the research, analyzed, and wrote the manuscript; J. Firn and J. Wells contributed to the analysis and writing; J. Herbohn contributed to the writing and provided logistical support and knowledge of Philippine forests. M. O. M. Moreno and A. Ferraren contributed to the data collection and provided expert knowledge of Philippine forests.

\section{Literature Cited}

Anderson, S. E., and J. S. I. Ingram. 1989. Tropical soil biology and fertility: a handbook of methods. C.A.B. International, Aberystwyth, UK.

Ashton, I. W., A. E. Miller, W. D. Bowman, and K. N. Suding. 2010. Niche complementarity due to plasticity in resource use: plant partitioning of chemical $\mathrm{N}$ forms. Ecology 91:3252-3260.

Baethgen, W. E., and M. M. Alley. 1989. A manual colorimetric procedure for measuring ammonium nitrogen in soil and plant Kjeldahl digests. Communications in Soil Science and Plant Analysis 20:961-969.

Baraloto, C., et al. 2012. Using functional traits and phylogenetic trees to examine the assembly of tropical tree communities. Journal of Ecology 100:690-701.

Barlow, J., et al. 2007. Quantifying the biodiversity value of tropical primary, secondary, and plantation forests. Proceedings of the National Academy of Sciences USA 104:18555-18560.

Bloor, J. M. G., and P. J. Grubb. 2004. Morphological plasticity of shade-tolerant tropical rainforest tree seedlings exposed to light changes. Functional Ecology 18:337-348.

Burns, J. H., and S. Y. Strauss. 2012. Effects of competition on phylogenetic signal and phenotypic plasticity in plant functional traits. Ecology 93:S126-S137.

Cadotte, M. W. 2014. Including distantly related taxa can bias phylogenetic tests. Proceedings of the National Academy of Sciences USA 111:E536.

Cadotte, M. W., J. Barlow, M. A. Nuñez, N. Pettorelli, and P. A. Stephens. 2017. Solving environmental problems in the Anthropocene: the need to bring novel theoretical advances into the applied ecology fold. Journal of Applied Ecology 54:1-6.

Cavender-Bares, J., D. D. Ackerly, D. A. Baum, and F. A. Bazzaz. 2004. Phylogenetic overdispersion in Floridian oak communities. American Naturalist 163:823-843.

Cavender-Bares, J., A. Keen, and B. Miles. 2006. Phylogenetic structure of floridian plant communities depends on taxonomic and spatial scale. Ecology 87:S109-S122.

Chapman, C. A. 1989. Primate seed dispersal: the fate of dispersed seeds. Biotropica 21:148-154.

Corlett, R. T. 2006. Figs (Ficus, Moraceae) in urban Hong Kong, South China. Biotropica 38:116-121.

Cornwell, W. K., D. W. Schwilk, and D. D. Ackerly. 2006. A trait-based test for habitat filtering: convex Hull volume. Ecology 87:1465-1471.

Fox, J. 2016. Effect displays for linear, generalized linear, and other models. http://www.r-project.org, http://socserv.socsci. momaster.ca/jfox/

Funk, J. L., J. E. Larson, G. M. Ames, B. J. Butterfield, J. Cavender-Bares, J. Firn, D. C. Laughlin, A. E. Sutton-Grier, L. Williams, and J. Wright. 2016. Revisiting the Holy Grail: using plant functional traits to understand ecological processes. Biological Reviews 92:1156-1173.

Gower, J. C. 1971. A general coefficient of similarity and some of its properties. Biometrics 27:857-871.

Grubb, P. J. 1977. The maintenance of species-richness in plant communities: the importance of the regeneration niche. Biological Reviews 52:107-145. 
Hector, A., et al. 2011. The Sabah Biodiversity Experiment: a long-term test of the role of tree diversity in restoring tropical forest structure and functioning. Philosophical Transactions of the Royal Society B 366:3303-3315.

Hipp, A. L., D. J. Larkin, R. S. Barak, M. L. Bowles, M. W. Cadotte, S. K. Jacobi, E. Lonsdorf, B. C. Scharenbroch, E. Williams, and E. Weiher. 2015. Phylogeny in the service of ecological restoration. American Journal of Botany 102:647-648.

Jung, V., C. Violle, C. Mondy, L. Hoffmann, and S. Muller. 2010. Intraspecific variability and trait-based community assembly. Journal of Ecology 98:1134-1140.

Kembel, S. W., P. D. Cowan, M. R. Helmus, W. K. Cornwell, H. Morlon, D. D. Ackerly, S. P. Blomberg, and C. O. Webb. 2010. Picante: R tools for integrating phylogenies and ecology. Bioinformatics 26:1463-1464.

Kraft, N. J. B., and D. D. Ackerly. 2010. Functional trait and phylogenetic tests of community assembly across spatial scales in an Amazonian forest. Ecological Monographs 80:401-422.

Laliberté, E., and P. Legendre. 2010. A distance-based framework for measuring functional diversity from multiple traits. Ecology 91:299-305.

Laliberté, E., P. Legendre, and B. Shipley. 2014. FD: measuring functional diversity from multiple traits, and other tools for functional ecology. R package version 1.0-12. https://cran.rproject.org/web/packages/FD/FD.pdf

Lamb, D., P. D. Erskine, and J. A. Parrotta. 2005. Restoration of degraded tropical forest landscapes. Science 310:1628-1632.

Langenberger, G., K. Martin, and J. Sauerborn. 2006. Vascular plant species inventory of a Philippine lowland rain forest and its conservation value. Biodiversity \& Conservation 15:1271-1301.

Lessard, J.-P., J. Belmaker, J. A. Myers, J. M. Chase, and C. Rahbek. 2012. Inferring local ecological processes amid species pool influences. Trends in Ecology \& Evolution 27:600-607.

Letcher, S. G. 2010. Phylogenetic structure of angiosperm communities during tropical forest succession. Proceedings of the Royal Society B 277:97-104.

Li, S.-P., M. W. Cadotte, S. J. Meiners, Z.-S. Hua, L. Jiang, and W.-S. Shu. 2015. Species colonisation, not competitive exclusion, drives community overdispersion over long-term succession. Ecology Letters 18:964-973.

Mayfield, M. M., and J. M. Levine. 2010. Opposing effects of competitive exclusion on the phylogenetic structure of communities. Ecology Letters 13:1085-1093.

Messier, J., B. J. McGill, and M. J. Lechowicz. 2010. How do traits vary across ecological scales? A case for trait-based ecology. Ecology Letters 13:838-848.

Murphy, J., and J. P. Riley. 1962. A modified single solution method for the determination of phosphate in natural waters. Analytica Chimica Acta 27:31-36.

Nguyen, H., J. Vanclay, J. Herbohn, and J. Firn. 2016. Drivers of tree growth, mortality and harvest preferences in speciesrich plantations for smallholders and communities in the tropics. PLoS ONE 11:e0164957.

Norden, N., S. G. Letcher, V. Boukili, N. G. Swenson, and R. Chazdon. 2011. Demographic drivers of successional changes in phylogenetic structure across life-history stages in plant communities. Ecology 93:S70-S82.

Pausas, J. G., and M. Verdú. 2010. The jungle of methods for evaluating phenotypic and phylogenetic structure of communities. BioScience 60:614-625.

Pérez-Harguindeguy, N., et al. 2013. New handbook for standardised measurement of plant functional traits worldwide. Australian Journal of Botany 61:167-234.

Pigot, A. L., and R. S. Etienne. 2015. A new dynamic null model for phylogenetic community structure. Ecology Letters 18:153-163.
Pinheiro, J., D. Bates, S. DebRoy, D. Sarkar, and R. C. Team. 2016. nlme: linear and nonlinear mixed effects models. $\mathrm{R}$ package version 3.1-124. http://CRAN.R-project.org/packa ge $=$ nlme

R Core Team. 2013. R: A language and environment for statistical computing. R Foundation for Statistical Computing, Vienna, Austria. www.R-project.org

Ricklefs, R. E. 2008. Disintegration of the ecological community. American Naturalist 172:741-750.

Schweizer, D., G. S. Gilbert, and R. Aizprua. 2014. Do young tropical restoration plantations exhibit a phylogenetic pattern that suggests the influence of biotic processes affecting species composition? PeerJ PrePrints 2:e625v621.

Schweizer, D., R. Machado, G. Durigan, and P. H. S. Brancalion. 2015. Phylogenetic patterns of Atlantic forest restoration communities are mainly driven by stochastic, dispersal related factors. Forest Ecology and Management 354:300-308.

Shooner, S., C. Chisholm, and T. J. Davies. 2015. The phylogenetics of succession can guide restoration: an example from abandoned mine sites in the subarctic. Journal of Applied Ecology 52:1509-1517.

Silvertown, J. 2004. Plant coexistence and the niche. Trends in Ecology \& Evolution 19:605-611.

Sniderman, J. M. K., and G. J. Jordan. 2011. Extent and timing of floristic exchange between Australian and Asian rain forests. Journal of Biogeography 38:1445-1455.

Swenson, N. G., and B. J. Enquist. 2009. Opposing assembly mechanisms in a neotropical dry forest: implications for phylogenetic and functional community ecology. Ecology 90:2161-2170.

Valiente-Banuet, A., and M. Verdú. 2007. Facilitation can increase the phylogenetic diversity of plant communities. Ecology Letters 10:1029-1036.

Verdú, M., L. Gómez-Aparicio, and A. Valiente-Banuet. 2012. Phylogenetic relatedness as a tool in restoration ecology: a metaanalysis. Proceedings of the Royal Society B 279:1761-1767.

Walters, M. B., and P. B. Reich. 1999. Low-light carbon balance and shade tolerance in the seedlings of woody plants: Do winter deciduous and broad-leaved evergreen species differ? New Phytologist 143:143-154.

Webb, C. O. 2000. Exploring the phylogenetic structure of ecological communities: an example for rain forest trees. American Naturalist 156:145-155.

Webb, C. O., D. D. Ackerly, and S. W. Kembel. 2008. Phylocom: software for the analysis of phylogenetic community structure and trait evolution. Bioinformatics 24:2098-2100.

Webb, C. O., D. D. Ackerly, M. A. McPeek, and M. J. Donoghue. 2002. Phylogenies and community ecology. Annual Review of Ecology and Systematics 33:475-505.

Webb, C. O., G. S. Gilbert, and M. J. Donoghue. 2006. Phylodiversity-dependent seedling mortality, size structure, and disease in a Bornean rain forest. Ecology 87:S123-S131.

Wikström, N., V. Savolainen, and M. W. Chase. 2001. Evolution of the angiosperms: calibrating the family tree. Proceedings of the Royal Society B 268:2211-2220.

Wills, J. 2020. Seedling diversity in actively and passively restored tropical forest understories. The University of Queensland. Data collection. https://doi.org/10.14264/uq1.2020.999

Wills, J., J. Herbohn, M. O. M. Moreno, M. S. Avela, and J. Firn. 2017. Next-generation tropical forests: reforestation type affects recruitment of species and functional diversity in a human-dominated landscape. Journal of Applied Ecology 54:772-783.

Wright, I. J., et al. 2004. The worldwide leaf economics spectrum. Nature 428:821-827. 
SUPPORTING INFORMATION

Additional supporting information may be found online at: http://onlinelibrary.wiley.com/doi/10.1002/eap.2286/full

\section{Data Availability}

Data used in the manuscript are available from The University of Queensland Repository UQ eSpace (Wills 2020) at: https://doi. org/10.14264/uq1.2020.999 


\section{University Library}

\section{- M M N E R VA A gateway to Melbourne's research publications}

Minerva Access is the Institutional Repository of The University of Melbourne

\section{Author/s:}

Wills, J;Herbohn, J;Wells, J;Maranguit Moreno, MO;Ferraren, A;Firn, J

Title:

Seedling diversity in actively and passively restored tropical forest understories

Date:

2021-03-01

Citation:

Wills, J., Herbohn, J., Wells, J., Maranguit Moreno, M. O., Ferraren, A. \& Firn, J. (2021).

Seedling diversity in actively and passively restored tropical forest understories.

ECOLOGICAL APPLICATIONS, 31 (3), https://doi.org/10.1002/eap.2286.

Persistent Link:

http://hdl.handle.net/11343/287351

License:

CC BY-NC-ND 